\title{
Price Stickiness and Markup Variations in Market Games
}

\author{
Guo Chen \\ Department of Economics, University of Kansas, Lawrence, KS, USA 66045, chenguo@ku.edu \\ C. Gizem Korpeoglu \\ University College London, School of Management, London, UK, E14 5AA, c.korpeoglu@ucl.ac.uk \\ Stephen E. Spear \\ Tepper School of Business, Carnegie Mellon University, Pittsburgh, PA 15213, ss1f@andrew.cmu.edu
}

\begin{abstract}
In this paper, we show that the Shapley-Shubik market game model with production naturally generates an equilibration mechanism that can accommodate price stickiness arising from strategic interactions of firms. Unlike New Keynesian models that show similar price stickiness results, the market game model does not require enforcing menu costs or other additional restraints on price adjustment mechanisms in order to generate price stickiness. As such, we suggest that the market game model can provide a good microfoundation for macroeconomic analysis. We then explicitly show the relationship between a typical firm's markup of price over marginal cost and its market share.

Key words: General Equilibrium, Market Game, Price Rigidity.

JEL Codes: D43, D51, E12.
\end{abstract}

\section{Introduction}

Contemporary macroeconomic theory has been built on the three pillars of imperfect competition, nominal price rigidity, and strategic complementarity. The stickiness of prices (and wages in particular) is a well-established empirical fact, with early observations about the phenomenon dating back to Alfred Marshall. Because the friction of price stickiness cannot occur in perfectly competitive markets, modern micro-founded (e.g., New Keynesian) models have been forced to abandon the standard Arrow-Debreu paradigm of perfect competition in favor of models where agents may influence market prices. Strategic complementarity enters the picture as a mechanism for explaining the kinds of coordination failures that lead to sustained slumps like the Great Depression or the aftermath of the 2007-2008 financial crisis. Early work by Cooper and John (1988) lay out the importance of these three features for macroeconomics.

The need for imperfect competition becomes particularly transparent when one notes the importance of firms' markups of prices over marginal costs in allowing for quantity adjustments independently of price adjustments in response to market shocks. This is because prices equal marginal 
costs in competitive markets, and any variation in quantities must be accompanied by variations in prices. For models with nominal rigidities to work, some degree of positive markups is necessary. The role of markups in macroeconomic fluctuations has been examined closely by Rotemberg and Woodford $(1991,1992,1999)$. These papers have formed the basis for virtually all of the follow-on work in the new classical synthesis, and its reliance on imperfectly competitive market structures coupled with the dynamic structure of the neoclassical growth model. In most of this work, imperfect competition is introduced by imposing monopolistic competition via the Dixit and Stiglitz (1977) (hereinafter DS) model.

The DS model provides a simple and tractable way to model price-setting behavior in an otherwise competitive setting that strips away the sophistication of strategic behaviors that appear in settings of tight oligopoly. At the time of its introduction, the tractability of this model offset concerns over the empirical fact of oligopoly (in many industries including grocery retailing, banking, transportation, energy, telecommunications, and media), though in fairness to Dixit and Stiglitz, we note that their original model was one of preferences for diversity, rather than specialization in production.

Interestingly, there was another model around at that time which showed how to take explicit account of imperfect competition and large firms in a general equilibrium setting, the market game model developed by Shapley and Shubik (1977) and extended to production economies by Dubey and Shubik (1977). The Shapley-Shubik market game (hereinafter, market game) model received quite a bit of attention in the general equilibrium literature of the 1980's and 1990's, but was not considered as an alternative to models of monopolistic competition in macroeconomics. While the DS model certainly had important early adoption advantages (particularly in its first appearance as a model of production specialization in trade theory), the sophistication of the market game model likely deterred its applications, despite its distinct claim to being the best general equilibrium extension of well-known models in industrial organization, in the sense of following the original Nash framework for showing equilibrium in non-cooperative games (see, for example, Dubey and Geanakoplos 2003).

We believe the market game model can provide a significantly better micro-foundation for macroeconomics than do either the conventional real business cycle (hereinafter RBC) models based on the neoclassical growth model, or New Keynesian (hereinafter NK) models based on the DS model. Our belief is premised on the following three facts. First, as noted above, it is a simple empirical fact that modern industrial economies are populated by large firms that interact strategically across different markets in which they operate. These strategic interactions have been widely studied in partial equilibrium contexts in the theory of Industrial Organization (hereinafter IO), but macroeconomics has routinely ignored this branch of economics in favor of simpler models 
involving either perfect competition (RBC models) or models of local monopoly (the DS model). The market game model has similarly been overlooked, despite its potential of allowing for significant extension of findings in the IO literature to the general equilibrium. From an empirical perspective, since the adoption of the monopolistic competition framework in macroeconomics, there has been a marked increase in industrial concentration. The President's Council of Economic Advisors Issue Brief (2016) documents concentration since the 1980's not only in technology industries (e.g., aerospace, microchip, operating system, software, and smart phone) but also in the traditional manufacturing and extractive industries, and in finance. As the report notes, some of this increase in concentration has been due to technological innovations and associated scale phenomena, and some has been due to mergers and acquisitions. Regardless of the cause, the new empiricism of market power suggests that economists should be paying more attention to the strategic interactions of large firms in oligopolistic market structures.

Second, oligopoly models allow the introduction of an additional strategic dimension beyond imperfectly competitive pricing markups, which makes possible equilibrating quantity adjustment processes - as we will show here - that do not require variation in prices, in some versions of the model. This is in marked contrast to the additional frictions required in DS-based models (menu costs or Calvo contracts) for price stickiness to occur. There are other papers that employ strategic models to incorporate or generate price stickiness. For example, Fershtman and Kamien (1987) study duopolistic competition in a model with a homogeneous good, and incorporate sticky prices by assuming that the desirability of the good is an exponentially weighted function of accumulated past consumption. Cellini and Lambertini (2007) extend Fershtman and Kamien (1987) by considering a dynamic oligopolistic game where goods are differentiated with sticky prices. Slade (1999) investigates the strategic implications of price adjustments, and empirically shows that strategic behavior aggravates price rigidity in a dynamic oligopoly. Both Carvalho (2006)'s model on heterogeneity in price stickiness and Fehr and Tyran (2008)'s model on limited rationality show that nominal rigidity prevails under strategic complementarity. Finally, Bhaskar (2002) provides a model of imperfect competition that produces a continuum of stable staggered price equilibria by introducing two levels of strategic interactions of firms within and across industries. Bhaskar (2002)'s model is the closest to ours in the sense that it shows how strategic interactions can end up generating price rigidities, albeit in terms of adjustment staggering rather than general nominal rigidity generated in our model.

Third, contemporary dynamic-stochastic-general-equilibrium (DSGE) models typically examine fluctuations in output, employment, and prices around a fixed steady state. This is done despite the fact that the data on business cycle fluctuations measure deviations in observed quantities from endogenously generated trend growth paths. Before macro models can be brought to data, 
then, the data itself must be detrended, usually based on ad hoc assumptions on the nature of economic growth. In RBC models, this is justified for the simple reason that long run growth in the neoclassical growth model must be assumed exogenously. In NK models, where (as Romer 1990 has shown) long-run growth is possible given the increasing returns to specialization inherent in the DS technology, macro applications of the model generally just ignore increasing returns and adopt the RBC practice of working with detrended data and stochastic steady states. The other well-known model of endogenous growth - the Schumpeterian model by Aghion and Howitt (1992) - has seen only minor applications at the intersection of IO and macroeconomics (see, for example, Aghion and Howitt 2000). The market game model, on the other hand, has the potential to allow for explicit consideration of growth in terms of its ability to accommodate increasingreturns-to-scale technologies, as well as the fact that it nests both DS and Aghion and Howitt (1992) models given the abstract specification of production activities in the model. While dealing explicitly with increasing-returns-to-scale technologies is more difficult than dealing with convex technologies, it is not intractable. In an earlier study, Korpeoglu and Spear (2016) extend the market game model with production to allow for increasing-returns-to-scale technologies, and show how imperfect competition in the market game remedies the standard problem that competitive firms operating under increasing-returns-to-scale technologies face of either wishing to produce infinite output, or, if restricted to marginal-cost pricing, needing to be subsidized to offset losses. This analysis also provides some weak results on the existence of equilibrium, though it should be no surprise that strong existence results are unattainable when technology dictates limits on the number of firms that can be active in equilibrium. (This paper is available as an online appendix to the current paper.)

In this paper, we show that the market game generates equilibria that have two important features. First, we show that when firms have market power, their market-shares in both input and output markets affect the first-order conditions of their best responses, in ways that resemble the effects of price changes. From this observation, we are able to establish that firm quantity adjustments (holding input prices fixed) can maintain the Nash equilibrium of the model in versions of the model that exhibit indeterminacy of the Nash equilibrium. Hence, these versions of the model naturally admit sticky prices, regardless of the mechanism(s) that might lead firms to want to keep input prices unchanging. To the best of our knowledge, this is a new result. Second, we show that there is a close relationship between any individual firm's markup of price over marginal cost and its market share. As we noted above, the case for positive markups in macroeconomic models has been argued persuasively by Rotemberg and Woodford (1991, 1992, 1999). The relationship between markups and market shares, however, has not received attention, to the best of our knowledge. Rotemberg and Woodford (1992), for example, consider a model of oligopoly, but 
focus on symmetric Nash equilibrium in which each firm's market share is the same. This allows them to make predictions about how markups change as a response to demand or productivity shocks. What the market game brings to the discussion of markups that is new, is the fact that markets populated by finite numbers of firms operating under possibly different technologies will generate data on markup movements over different equilibria that can vary positively, negatively, variably, or not at all over business-cycle-like expansions and contractions. This is interesting in light of recent work by Nekarda and Ramey (2013) showing that "updated empirical methods and data" indicate that markups are weakly procyclic or acyclic, in contrast to the results found in the earlier work on markups and productivity co-movements.

The remainder of the paper is organized as follows. Section 2 lays out the basic market game model; Section 3 provides the detailed analysis of price stickiness and markup variations; and Section 4 concludes.

\section{Model}

We work initially with a standard market game model with production along the lines first considered by Dubey and Shubik (1977). In this section, we elaborate on the model ingredients. Most of our formulation of the model and our notation will follow that of Peck and Shell (1990) and Peck et al. (1992).

\subsection{Agents}

The economy consists of two types of agents: consumers ("she") and firms ("it"). There are $M<\infty$ consumers who are endowed with production inputs $\bar{e}_{i} \in \mathbb{R}_{+}^{N}$ and sell these inputs to firms that produce outputs from which consumers derive utility. For simplicity, we assume that consumers derive no direct utility from the consumption of their input endowments.

Preferences of consumers are defined over output goods vectors $x_{i} \in \mathbb{R}_{+}^{J}$. Utility functions are assumed to be at least twice continuously differentiable, strictly increasing, strictly concave, and satisfy Inada conditions. There are $K_{j}<\infty$ firms of finitely many types $j \in\{1,2, \ldots, J\}$ that produce output good $j$ using a production technology specified by a production function $q_{k_{j}}^{j}=f_{k_{j}}\left(\varphi_{k_{j}}\right)$, where $\varphi_{k_{j}} \in \mathbb{R}_{+}^{N}$ is the vector of inputs for firm $k_{j} \in\left\{1,2, \ldots, K_{j}\right\}$ in production sector $j \in\{1,2, \ldots, J\}$, and each production function is twice continuously differentiable and strictly quasi-concave. We will denote the total number of firms by $\mathcal{J}=\sum_{j=1}^{J} K_{j}$. We assume that consumers are exogenously endowed with ownership shares of each firm. Specifically, we let $\theta_{i}^{k_{j}}$ be consumer $i$ 's ownership share of firm $k_{j}$ in sector $j$. 
2.1.1. Firm actions. Firms purchase production inputs from consumers and use them to produce outputs, which they then sell back to consumers based on their expectations of prices they can receive for their outputs. Since firms are not endowed with production inputs, they must bid for these inputs on input trading posts (which are endemic to the market game). We assume that firms aim to maximize their profits. ${ }^{1}$ We let $p^{j}$ be the price of output good $j$, and $r^{n}$ be the price of input good $n$, and $r=\left(r^{1}, r^{2}, \ldots, r^{N}\right)$ be the vector of input prices. The profit of firm $k_{j}$ is then

$$
\pi_{k_{j}}=p^{j} q_{k_{j}}^{j}-\sum_{n=1}^{N} r^{n} \varphi_{k_{j}}^{n}=p^{j} f_{k_{j}}\left(\varphi_{k_{j}}\right)-r \cdot \varphi_{k_{j}} .
$$

Input prices are determined on input trading posts. We let $w_{k_{j}}^{n}$ denote firm $k_{j}$ 's bid on input trading post $n \in\{1,2, \ldots, N\}$, and $w_{k_{j}}=\left(w_{k_{j}}^{1}, w_{k_{j}}^{2}, \ldots, w_{k_{j}}^{N}\right) \in \mathbb{R}_{+}^{N}$ denote firm $k_{j}$ 's vector of bids for inputs. $^{2}$ The aggregate bid at trading post $n$ is $W^{n}=\sum_{j=1}^{J} \sum_{k_{j}=1}^{K_{j}} w_{k_{j}}^{n}$. As is standard, we let $W_{-k_{j}}^{n}$ denote the aggregate bid at trading post $n$ except for the bid of firm $k_{j}$. Moreover, we let $e_{i}^{n}$ denote consumer $i$ 's offer at input trading post $n$, and $E^{n}=\sum_{i=1}^{M} e_{i}^{n}$ denote the aggregate offer at input trading post $n$. Then, the price of input good $n$ is then defined as $r^{n}=\frac{W^{n}}{E^{n}}$. Firm $k_{j}$ 's allocation of input good $n$ is given by its own bid for the input divided by the price of the input

$$
\varphi_{k_{j}}^{n}=\frac{w_{k_{j}}^{n}}{r^{n}}=w_{k_{j}}^{n} \frac{E^{n}}{W^{n}} .
$$

This is just the standard market game rule that allocates each firm the same proportion of the aggregate offer of the input good as its bid is to the aggregate bid. Firms earn unit of account revenues from the sale of their outputs on trading posts for output goods. Given $q_{k_{j}}^{j}=f_{k_{j}}\left(\varphi_{k_{j}}\right)$ for $j \in\{1, \ldots, J\}$, firm $k_{j}$ will offer all of its output on the output trading post $j$, so we can define the aggregate offer at trading post $j$ as $Q^{j}=\sum_{k_{j}=1}^{K_{j}} q_{k_{j}}^{j}$. As before, we let $Q_{-k_{j}}^{j}$ denote the aggregate offer at trading post $j$ except for the offer of firm $k_{j}$. Given the price $p^{j}$ for the output good $j$, firm $k_{j}$ can spend $p^{j} q_{k_{j}}^{j}$ units of account on the purchase of input goods. Hence, firm $k_{j}$ faces the following budget constraint for its bids on inputs

$$
\sum_{n=1}^{N} w_{k_{j}}^{n} \leq p^{j} q_{k_{j}}^{j}
$$

Note that substituting for $w_{k_{j}}^{n}$ from (2) into (3) yields

$$
\sum_{n=1}^{N} \varphi_{k_{j}}^{n} r^{n} \leq p^{j} q_{k_{j}}^{j} \Rightarrow \pi_{k_{j}}=p^{j} q_{k_{j}}^{j}-\sum_{n=1}^{N} \varphi_{k_{j}}^{n} r^{n} \geq 0,
$$

which means that firm $k_{j}$ 's profit cannot be negative. If the firm's budget constraint (3) is not satisfied, then its input allocation is zero and all of its offers are confiscated.

\footnotetext{
${ }^{1}$ In the absence of perfect competition, it is well known that shareholders can disagree on the objective of the firm they own. As it is beyond the scope of this paper to justify that profit maximization is the correct objective for the firm operating under increasing-returns-to-scale technology, we just take this assumption as it is.

${ }^{2}$ The fictional trading posts introduced by Shapley and Shubik (1977) are essentially a metaphor for flows of expenditure and product between traders. By collecting these flows for specific markets on "trading posts," it simplifies the actions of choosing demand and supply allocations and streamlines the exposition of the market game form. In equilibrium, though, it is only the flows of expenditure and product that matter, not where they take place.
} 
2.1.2. Consumer actions. Consumers bid on trading posts for output goods. Because consumers derive no utility from the consumption of their input endowments, but receive income from selling these inputs, consumers will sell as much of their endowments as possible to firms. Consumer $i$ 's income from the sale of her input endowments, then, is given by $r \cdot e_{i}=\sum_{n=1}^{N} r^{n} e_{i}^{n}=\sum_{n=1}^{N} \frac{W^{n}}{E^{n}} e_{i}^{n}$, where the aggregate bid $W^{n}$ on the input market $n$ is determined by firms' production decisions. In addition to their income from the sale of input endowments, consumers also receive (exogenously given) shares of profits from firms they own, so that consumer $i$ 's total income is

$$
y_{i}=\sum_{n=1}^{N} \frac{W^{n}}{E^{n}} e_{i}^{n}+\sum_{j=1}^{J} \sum_{k_{j}=1}^{K_{j}} \theta_{i}^{k_{j}} \pi_{k_{j}} .
$$

Note that if we had a small number of consumers, given the arbitrary distribution of ownership shares across consumers, consumers might want firms they own to deviate from profit maximization in order to increase the value of their sales of input endowments. This failure of shareholder unanimity in models with imperfect competition is well known. As we do not provide any insight into this issue here, we will simply assume that consumers take the value of their endowment offers and the value of their profit shares as given. This can be justified more rigorously by assuming that the number of consumers is much higher than the number of firms, so that the ratio $\frac{e_{i}^{n}}{E^{n}}$ in (4) is negligible, and that ownership of firms is diffusely distributed. We let $b_{i}^{j}$ denote consumer $i$ 's bid on output trading post $j \in\{1,2, \ldots, J\}$, and $b_{i}=\left(b_{i}^{1}, b_{i}^{2}, \ldots, b_{i}^{J}\right) \in \mathbb{R}_{+}^{J}$ denote consumer $i$ 's vector of bids for outputs. The aggregate bid at trading post $j$ is $B^{j}=\sum_{i=1}^{M} b_{i}^{j}$. As above, we let $B_{-i}^{j}$ denote the aggregate bid at trading post $j$ except for the bid of consumer $i$. The price of output good $j$ is then defined as the ratio of the total bid for the output good $j$ to the total offer of the output good $j$, i.e., $p^{j}=\frac{B^{j}}{Q^{j}}$. Consumer $i$ 's allocation of output good $j$ is given by her own bid for the output divided by the price of the output

$$
x_{i}^{j}=\frac{b_{i}^{j}}{p^{j}}=b_{i}^{j} \frac{Q^{j}}{B^{j}} .
$$

This is just the standard market game rule that gives each consumer the same proportion of the aggregate offer of the output good as her bid is to the aggregate bid. Consumer $i$ faces the following budget constraint for bids on outputs

$$
\sum_{j=1}^{J} b_{i}^{j} \leq y_{i}=\sum_{n=1}^{N} \frac{W^{n}}{E^{n}} e_{i}^{n}+\sum_{j=1}^{J} \sum_{k_{j}=1}^{K_{j}} \theta_{i}^{k_{j}} \pi_{k_{j}} .
$$

As with firms, if the consumer's budget constraint is violated, her allocation is zero and all of her offers are confiscated.

\subsection{Market Game and Nash Equilibrium}

With these definitions and characterization of agents in the model, we can now formally define the market game $\Gamma$. 
Definition 1. Consumer $i$ 's strategy set is

$$
S_{i}=\left\{\left(b_{i}, e_{i}\right) \in \mathbb{R}_{+}^{2 J} \mid e_{i}<\bar{e}_{i}\right\} \text { for } i \in\{1,2, \ldots, M\} .
$$

Firm $k_{j}$ 's strategy set is

$$
S_{k_{j}}=\left\{w_{k_{j}} \in \mathbb{R}_{+}^{N}\right\} .
$$

The full strategy set that then defines the offer-constrained game $\Gamma(\hat{\mathbf{e}})$ is

$$
S=\times_{i=1}^{M} S_{i} \times_{k_{j}=1, j=1}^{K_{j}, J} S_{k_{j}} .
$$

Definition 2. A Nash equilibrium of the simultaneous-move market game consists of consumers' bids for outputs, and firms' bids for inputs given expectations of other agents' actions such that

1. All agents' bids are best responses given their expectations of other agents' bids, of consumers' input offers, and of firms' output offers;

2. The best responses are consistent with all agents' expectations of other agents' actions.

While choosing its profit-maximizing bids, firm $k_{j}$ takes the aggregate offer $E^{n}=\sum_{i=1}^{M} e_{i}^{n}$ as given, but takes other firms' (including those of other sectors) bids for inputs into account. Firm $k_{j}$ maximizes its profit in (1) subject to the allocation rule in (2) and budget constraint in (3) given the input price $r^{n}=W^{n} / E^{n}$ and output price $p^{j}=B^{j} / Q^{j}$. Plugging constraints (2) and (3) into the objective (1), we obtain the following unconstrained profit maximization problem:

$$
\max _{w_{k_{j}}} \frac{B^{j}}{Q^{j}} f_{k_{j}}\left(\left[w_{k_{j}}^{1} \frac{E^{1}}{W^{1}}, \ldots, w_{k_{j}}^{N} \frac{E^{N}}{W^{N}}\right]\right)-\sum_{n=1}^{N} w_{k_{j}}^{n},
$$

Note that $(7)$ is firm $k_{j}$ 's best response to other firms' actions. Taking first-order conditions gives

$$
\frac{B^{j}}{Q^{j}} \frac{\partial f_{k_{j}}}{\partial \varphi_{k_{j}}^{n}}\left[\frac{E^{n}}{W^{n}}-\frac{w_{k_{j}}^{n} E^{n}}{\left(W^{n}\right)^{2}}\right]-\frac{B^{j} q_{k_{j}}^{j}}{\left(Q^{j}\right)^{2}} \frac{\partial f_{k_{j}}}{\partial \varphi_{k_{j}}^{n}}\left[\frac{E^{n}}{W^{n}}-\frac{w_{k_{j}}^{n} E^{n}}{\left(W^{n}\right)^{2}}\right]-1=\frac{B^{j}}{Q^{j}} \frac{\partial f_{k_{j}}}{\partial \varphi_{k_{j}}^{n}} \frac{E^{n} W_{-k_{j}}^{n}}{\left(W^{n}\right)^{2}} \frac{Q_{-k_{j}}^{j}}{Q^{j}}-1=0 .
$$

Plugging $p^{j}=B^{j} / Q^{j}$ and $r^{n}=W^{n} / E^{n}$ into (8) gives

$$
\frac{p^{j}}{r^{n}} \frac{\partial f_{k_{j}}}{\partial \varphi_{k_{j}}^{n}} \frac{W_{-k_{j}}^{n}}{W^{n}} \frac{Q_{-k_{j}}^{j}}{Q^{j}}-1=0
$$

Note that if the market contains a very large number of firms, ratios $W_{-k_{j}}^{n} / W^{n}$ and $Q_{-k_{j}}^{j} / Q^{j}$ in (9) will be almost one, and hence (9) boils down to $p^{j} \frac{\partial f_{k_{j}}}{\partial \varphi_{k_{j}}^{n}}=r^{n}$, which states that the value of the marginal product of input good $n$ is equal to the price of input good $n$.

While choosing her utility-maximizing bids, consumer $i$ takes the aggregate output $Q^{j}$ as given, but takes other consumers' bids for outputs into account. Consumer $i$ maximizes her utility $u_{i}\left[x_{i}\right]$ subject to the allocation rule in (5) and budget constraint in (6). Plugging the constraint (5) into the objective yields the following budget-constrained utility maximization problem:

$$
\begin{aligned}
& \max _{b_{i}} u_{i}\left[b_{i}^{1} \frac{Q^{1}}{B^{1}}, \ldots, b_{i}^{J} \frac{Q^{J}}{B^{J}}\right] \\
& \text { s.t. } \sum_{j=1}^{J} b_{i}^{j} \leq \sum_{n=1}^{N} \frac{W^{n}}{E^{n}} e_{i}^{n}+\sum_{j=1}^{J} \sum_{k_{j}=1}^{K_{j}} \theta_{i}^{k_{j}}\left[\frac{B^{j}}{Q^{j}} q_{k_{j}}^{j}-r \cdot \varphi_{k_{j}}\right] .
\end{aligned}
$$


Note that (10)-(11) is consumer $i$ 's best response to other consumers' actions. Taking first-order conditions gives

$$
\frac{\partial u_{i}}{\partial x_{i}^{j}}\left[\frac{Q^{j}}{B^{j}}-\frac{b_{i}^{j} Q^{j}}{\left[B^{j}\right]^{2}}\right]+\lambda\left[\frac{\sum_{k_{j}=1}^{K_{j}} \theta_{i}^{k_{j}} f_{k_{j}}}{Q^{j}}-1\right]=\frac{\partial u_{i}}{\partial x_{i}^{j}}\left[\frac{Q^{j}}{B^{j}} \frac{B_{-i}^{j}}{B^{j}}\right]+\lambda\left[\frac{\sum_{k_{j}=1}^{K_{j}} \theta_{i}^{k_{j}} f_{k_{j}}}{Q^{j}}-1\right]=0,
$$

where $\lambda$ is the Lagrange multiplier of consumer $i$ 's budget constraint in (11). Note that we do not need to consider the effect of a change in consumer $i$ 's bid on input prices because of the envelope theorem as applied to firms' profit maximization problems. Finally, note that if the market contains a very large number of firms, the total offer $Q^{j}$ on output trading post $j$ approaches infinity, and if the market contains a very large number of consumers, the ratio $B_{-i}^{j} / B^{j}$ approaches one. Then, the consumer first-order condition (12) boils down to what we get in the competitive limit, the

ratio of marginal utility to the price is equal to the Lagrange multiplier, i.e., $\frac{\partial u_{i} / \partial x_{i}^{j}}{p^{j}}=\lambda$, where $p^{j}=B^{j} / Q^{j}$.

\section{Analysis}

In this section, we provide the analysis of price stickiness and markup variations. Korpeoglu and Spear (2016) (see the online appendix) show conditions for the existence of a Nash equilibrium for a production market game with arbitrary returns-to-scale-technologies. Unlike in the case of strictly convex technologies, there are no strong existence results in the case of increasing-returns-to-scale technologies, for the simple reason that the non-negativity constraint on profits can become binding when there are many increasing-returns-to-scale firms in the market. For our purposes here, then, we will simply assume that there can be increasing-returns-to-scale firms in each production sector together with standard constant or decreasing-returns-to-scale firms, and that the Nash equilibrium associated with the aggregate input endowment $E$ exists.

The result we present here is essentially a comparative static result showing that if firms cannot (or do not wish to) vary input prices, they can accommodate shocks to production or demand via adjustments in output. This is conceptually no different from what occurs in competitive models. What is new with the market game is the fact that some of this accommodation can be achieved via adjustments in firm market shares on both input and output markets. In the presence of coordination indeterminacies, this new adjustment mechanism can give rise to novel equilibrium behavior in the model.

We will consider two variants of the model. The first is the standard, simultaneous-move Shapley and Shubik (1977) model with production (as laid out above). It is well-known that in pure exchange versions of this model, there are a continuum of Nash equilibria due to the fact that agents in the model choose both bids and offers. This choice is indeterminate, however, since the first-order conditions with respect to bids or offers are the same. In imperfectly competitive markets, one of 
the choices between bids and offers is redundant for individual agents, though it affects prices in the model via variations in market thickness (see Peck and Shell 1991 or Peck et al. 1992 for details). In the production model, no such indeterminacy is possible for the simple fact that consumers earn income from the sale of their endowments. Hence, in this version of the model, the comparative static result shows that any accommodation to shocks (with sticky prices) will necessarily involve some degree of involuntary unemployment of input resources. We conjecture that same form of neo-Keynesian coordination failure equilibria can be generated in the model, though not without a significantly more sophisticated (likely search-theoretic) micro-foundation for the input markets, which we do not pursue here.

In the second variant of the model, we introduce a real indeterminacy by allowing agents to short sell their endowments by offering more than they own, subject to the constraint that in equilibrium, they must buy back the short amount. This version of the model is based on the one originally introduced by Peck and Shell (1990). Peck and Shell (1990) note that this version of the market game must be modified by changing the bankruptcy rules so that if any consumer does not satisfy her budget constraint, every consumer is forced to consume her endowment. This rule change is necessary because for very large short sales, the game "referee" may not be able to find an equilibrium using only the resources of non-bankrupt consumers. Since this variation on the production market game does not require any consumer to offer less than her full endowment, it is consistent with the non-cooperative incentive consumers in the production game have for earning income.

For both versions of the game, the starting point for our analysis is the individual firm's firstorder conditions for profit maximization. For firm $k_{j}$, these can be written as

$$
p^{j}\left(\frac{Q_{-k_{j}}^{j}}{Q^{j}}\right) D_{\varphi} f_{k_{j}}-\hat{W} \hat{W}_{-k_{j}}^{-1} r=0 .
$$

The significance of writing the first-order conditions this way stems from the fact that variations in the terms $\hat{W} \hat{W}_{-k_{j}}^{-1} r$ and $p^{j} \frac{Q_{-k_{j}}^{j}}{Q^{j}}$ affect the firm's optimal choice, in the same way that variations in the input output prices do for perfectly competitive firms. Note also that $\frac{Q_{-k_{j}}^{j}}{Q^{j}}=1-\frac{q_{k_{j}}^{j}}{Q^{j}}$, where $\frac{q_{k_{j}}^{j}}{Q^{j}}$ is firm $k_{j}$ 's market share on the output market $j$, and $\frac{W_{-k_{j}}^{n}}{W^{n}}=1-\frac{w_{k_{j}}^{n}}{W^{n}}$, where $\frac{w_{k_{j}}^{n}}{W^{n}}$ is firm $k_{j}$ 's market share on the input market $n$. Since market shares can be varied independently of aggregate bids on output or expenditures on inputs, this suggests the possibility of altering firms equilibrium output quantities via adjustments in market shares without changing prices.

To analyze the possibility of price preserving perturbations in the market game, we first note that since we only have $(\mathcal{J}-1) N$ independent expenditure shares, we would need another $N$ variables in order to make a full-rank perturbation of the system of equations consisting of firm firstorder conditions. We can pick up these variables by allowing for variations in the firms' aggregate 
expenditures on inputs (which we can think of as flexible inside money or credit in the market game setting, or as a monetary policy action in a macro interpretation of the model). To get a price rigidity result, we need to append the condition

$$
r-\hat{W} E=0
$$

(where $E$ is the vector of aggregate input offers) to the firm first-order conditions, giving us a system of $\mathcal{J} N+N$ equations in $\mathcal{J} N$ variables. To get a full-rank perturbation of this system, then, we need an additional $N$ variables. We cannot use the output market shares as these variables as they are not independent of firm output quantities. In a partial equilibrium setting, we might think of using the output prices themselves as variables (assuming there are at least as many output goods as there are input goods). But, in a general equilibrium setting, we need the output prices (or, equivalently, the aggregate bids of consumers for output goods) to ensure equilibrium in the output markets. This logic, then, gives us our first result.

Proposition 1. For the simultaneous-move market game, equilibrium responses to demand or technology shocks will generically (in production functions) require variations in prices.

The genericity argument here simply requires noting that if some shock left (say) input prices constant, then the firm would be moving up or down an expansion path homothetically. An arbitrarily small perturbation in the firm's production function will then destroy this homotheticity.

We can get a full rank perturbation that keeps input prices constant if we have an indeterminacy in consumers' aggregate offers, since this gives us the additional $N$ variables we need. So, we now consider the Peck and Shell (1990) short-sale variant of the model that gives rise to indeterminacy. As we noted above, in the short-sale model, consumers are allowed to offer more than their total endowment on the input market, as long as they buy back the excess offer. This gives consumers the opportunity to affect market shares, which will matter if the input markets are strategic, i.e., if firms are not negligible.

As Peck and Shell (1990) note, the key to analyzing the short-sale version of the market game is the so-called offer-constrained game, in which consumers' offers are fixed exogenously, and viewed as parameters the underlying game. The utility of the offer-constrained game stems from the fact that, with bid-offer indeterminacy, any equilibrium in the offer-constrained game will also be an equilibrium in the unconstrained game.

We define the offer-constrained game formally as follows. Consumer $i$ 's (offer-constrained) strategy set is

$$
S_{i}\left(\hat{e}_{i}\right)=\left\{\left(b_{i}, e_{i}\right) \in \mathbb{R}_{+}^{J+N} \mid e_{i}=\hat{e}_{i}\right\} \text { for } i \in\{1, \ldots, M\} .
$$

Firm $\mathrm{k}_{j}^{\prime} s$ strategy set is

$$
S_{k_{j}}=\left\{w_{k_{j}} \in \mathbb{R}_{+}^{N}\right\} .
$$


The full strategy set that then defines the offer-constrained game $\Gamma(\hat{e})$ is

$$
S(\hat{e})=\times_{i=1}^{M} S_{i}\left(\hat{e}_{i}\right) \times_{k_{j}=1, j=1}^{K_{j}, J} S_{k_{j}} .
$$

A Nash equilibrium of the simultaneous-move offer-constrained market game consists of consumers' bids for outputs, and firms' bids for inputs given expectations of other agents' actions such that

1. All agents' bids are best responses given their expectations of other agents' bids, of consumers' input offers, and of firms' output offers;

2. The best responses are consistent with all agents' expectations of other agents' actions.

For the short-sale game, we need to modify the punishment (as in Peck and Shell 1990) to state that if any consumer violates her budget constraint, all agents' allocations revert to their endowments. In the short-sale game, we would also formally modify the definition of the consumer's strategy set to require that $\hat{e}_{i} \geq \bar{e}_{i}$, where, as before, $\bar{e}_{i}$ is consumer $i$ 's endowment vector.

With these preliminaries, we can now show our main result.

THEOREM 1. Generically, there exist solutions to the production side equilibrium equations in variables consisting of firm input wage bill shares, aggregate input quantities, and aggregate input bids, in a neighborhood of any given offer-constrained Nash equilibrium for the economy.

Proof: See Appendix A.

Given that output prices variables are not used to equilibrate the production side of the economy, they will continue to serve their usual purpose in equilibrating the demand side of the model. One can apply conventional general equilibrium techniques to show a similar generic transversality result for this equilibration process, though since this is not germane to our results, we do not pursue it here. Since the proof of this result makes use of the implicit function theorem, we can also include perturbations in actual endowments as well as offers to the list of equilibration parameters, although this result is tangential to our basic results. We also conjecture that a similar result could be obtained if firms were also allowed to offer, as well as bid for input goods, but do not pursue that here.

\subsection{Discussion}

The most striking thing about the continuum of equilibria generated in the short-sale model is the fact that the economy is always at full employment of input resources. The theorem implies that variations in short-sale amounts will lead to adjustments in firm market shares (on both input and output markets), which can lead to non-trivial variations in total output. One could extend this result to a stochastic market game in which the short-sale offers varied according to some extrinsic random variable (i.e., a sunspot), as in Peck and Shell (1991). This would result in a stochastic general equilibrium for the model in which individual firm market shares are constantly 
changing. As we will show in the next section, this variation in market shares leads, in turn, to variations in the observed mark-ups that imperfectly competitive firms charge. In a heterogenous returns-to-scale environment, then, one of the key relationships in New Keynesian macro models the variation of mark-ups over the business cycle - will be disrupted.

\subsection{Markup Variations}

As we noted in Introduction, it is a stylized fact in NK macro models that markups vary countercyclically. In a recent study, as Nekarda and Ramey (2013) note, however, the estimation of marginal costs from available data is quite tricky, and early attempts to study markup variations over the business cycle ended up relying on theoretical relationships (based typically on DS-based NK models) for the specification of marginal costs. Nekarda and Ramey (2013) revisit the question of cyclical movements in markups using updated adjustments of inputs to production functions typically used in such studies, and using a combination of aggregate and manufacturing-specific data. Contrary to the conventional stylized fact, they establish that markups are unconditionally procyclic. Specifically, they find that monetary, government spending, and technology shocks lead to procyclical markups, and consumer demand shocks lead to slightly procyclical or acyclical markups. We will show in this section that the market game model also makes specific predictions about markup variation in response to (comparative static) expansions or contractions, but, because firms can exhibit heterogeneity in the returns-to-scale properties of their technologies, the aggregate observed markup variation can be quite different from that of any particular firm.

We start by writing the firm's cost-minimization problem:

$$
\min _{w} \iota \cdot w \text { s.t. } f\left(\hat{W}^{-1} \hat{E} w\right) \geq q
$$

where the vector $\iota=(1,1, \ldots, 1)$ is a sum vector. The first-order conditions of this problem are

$$
\iota^{T}-\lambda D f^{T} \hat{W}^{-2} \hat{W}_{-k} \hat{E}=0,
$$

which reduces to

$$
r^{T} \hat{W} \hat{W}_{-k}^{-1}-\lambda D f^{T}=0 .
$$

Since the Lagrange multiplier in the cost-minimization problem is just the marginal cost, if we assume that the production function is homogeneous of degree $\delta$, then by direct calculation we have that

$$
M C(q)=\lambda=\frac{1}{\delta q} r^{T} \hat{W} \hat{W}_{-k}^{-1} \varphi(q) .
$$

To calculate the markup, we note from the first-order conditions for profit maximization that

$$
\hat{W} \hat{W}_{-k}^{-1} r=p \frac{Q_{-k}}{Q} D f .
$$

Combining profit maximization and cost minimization results, we have

$$
\lambda=\frac{1}{\delta q} p \frac{Q_{-k}}{Q} D f \cdot \varphi(q)=p \frac{Q_{-k}}{Q} .
$$


Hence, we obtain

$$
\frac{p}{\lambda}=\frac{Q}{Q_{-k}}=\frac{1}{\left[1-\frac{q_{k}}{Q}\right]} .
$$

This result shows that if firm $k$ 's market share increases, its markup also increases. Because the firm's equilibrium market share depends on its own and other firms' technologies, we have no a priori reason to believe that measures of average market shares (and hence observed average markups) move in any systematic way during expansions or contractions. In the next section, we show in two examples that individual firm market shares can increase or decrease as we move from low-input-use equilibrium to high-input-use equilibrium.

\subsection{Example 1}

In this section, we provide a simple example with two firms that use a single input to produce a single output good, and carry through the equilibration calculations for firm-side input perturbations, without taking explicit account of the equilibration required on the demand side of the model. We let $L\left(=L_{1}+L_{2}\right)$ denote the exogenously given aggregate offer of the input (hereinafter, labor). Production functions of firm 1 and 2 are

$$
q_{1}=f_{1}\left(L_{1}\right)=L_{1}^{2} \text { and } q_{2}=f_{2}\left(L_{2}\right)=\left[L_{2}-\bar{K}\right]^{\alpha},
$$

respectively, where $0<\alpha<1$ and $\bar{K}$ is a fixed real cost of production for firm 2 . We let $Q\left(=q_{1}+q_{2}\right)$ denote the aggregate output. We also let $w_{i}$ denote firm $i$ 's bid on labor and $W\left(=w_{1}+w_{2}\right)$ denote the aggregate bid on labor. As in the model, the price of input is $r=W / L$, and the price output is $p=B / Q$. The input allocations of firm 1 and 2 are

$$
L_{1}=\frac{w_{1}}{r}=\frac{w_{1}}{W} L \text { and } L_{2}=\frac{w_{2}}{r}=\frac{w_{2}}{W} L,
$$

respectively. Firms take the aggregate offer of labor $L$ as given, but take the other firm's bid on labor into account. Firm $i$ 's best response to the other firm's action is a solution to the following profit maximization problem:

$$
\max _{w_{i}} \frac{B}{Q} q_{i}-w_{i} \text { s.t. } w_{i} \leq \frac{B}{Q} q_{i}, L_{i}=w_{i} \frac{L}{W}, q_{i}=f_{i}\left(L_{i}\right) .
$$

The first constraint requires nonnegative profits. The first-order condition of firm 1 is

$$
\frac{B}{Q} f_{1}^{\prime}\left(L_{1}\right)\left[\frac{L}{W}-w_{1} \frac{L}{W^{2}}\right]+B f_{1}\left(L_{1}\right)\left[-\frac{1}{Q^{2}}\right]\left[f_{1}^{\prime}\left(L_{1}\right)\left(\frac{L}{W}-w_{1} \frac{L}{W^{2}}\right)\right]-1=0 .
$$

Reorganizing (15), we get

Substituting (13) and (14) yields

$$
\frac{B}{Q^{2}} \frac{w_{2} L}{W^{2}}\left[f_{2}\left(L_{2}\right) f_{1}^{\prime}\left(L_{1}\right)\right]-1=0
$$

$$
2 \frac{B L^{2}\left[\left(\frac{w_{2}}{W}\right) L-\bar{K}\right]^{\alpha}}{Q^{2}} \frac{w_{2}}{W} \frac{w_{1}}{W^{2}}=1 .
$$

We let $s_{i}=w_{i} / W$ as $w_{i} / W$ is firm $i$ 's share of the input. Plugging $r=W / L$ and $p=B / Q$ gives

$$
2 \frac{p}{r} \frac{L\left[s_{2} L-\bar{K}\right]^{\alpha}}{Q} s_{2} s_{1}=1
$$


By symmetry, the first-order condition of firm 2 is

$$
\frac{B}{Q^{2}} \frac{w_{1} L}{W^{2}}\left[f_{1}\left(L_{1}\right) f_{2}^{\prime}\left(L_{2}\right)\right]-1=0 .
$$

Substituting (13), (14), and $r=W / L$ and $p=B / Q$, we get

$$
\alpha \frac{p}{r} \frac{s_{1}}{Q}\left[s_{1} L\right]^{2}\left[s_{2} L-\bar{K}\right]^{\alpha-1}-1=0 .
$$

Solving (16) and (17) together, we obtain

$$
2 s_{2}\left[s_{2} L-\bar{K}\right]=\alpha s_{1}^{2} L .
$$

If we let $\hat{\alpha}=\frac{\alpha}{2}, s_{2}=s$ and $s_{1}=1-s$, this condition reduces to the following simple quadratic form $(1-\hat{\alpha}) L s^{2}+[2 \hat{\alpha} L-\bar{K}] s-\hat{\alpha} L=0$. Furthermore, if $\bar{K}=0$, it reduces to $s=\frac{\sqrt{\hat{\alpha}}}{\sqrt{\hat{\alpha}}+1}$. Substituting back into (16) or (17) will then determine what output price must be, given any equilibrium input levels including input price. Thus, if $\bar{K}=0$ and $\alpha=0.5$, both firms make positive profits. Deviations away from $\bar{K}=0$ or $\alpha=0.5$ can lead to firm equilibrium in which firms make negative profits. Obviously, in a dynamic context, this would necessitate that such firms make a decision on whether to remain in the market.

\subsection{Example 2}

In this section, we provide an example with three firms that use a single input (i.e., labor) to produce a single output. Interestingly, this example explicitly shows the existence of multiple equilibria even in the one-input, one-output model (for similar examples, see Benhabib and Farmer 1994 and references therein). Production functions of firm 1, 2, and 3 are as follows:

$$
\begin{array}{ll}
\text { Firm1 : } & q_{1}=f_{1}\left(L_{1}\right)=A \cdot L_{1}^{2}, \\
\text { Firm2: } & q_{2}=f_{2}\left(L_{2}\right)=B \cdot L_{2}^{\alpha}, \quad 0<\alpha<1 \\
\text { Firm3 : } & q_{3}=f_{3}\left(L_{3}\right)=C \cdot L_{3} .
\end{array}
$$

We next consider profit maximization problems of these firms. Firm $i$ 's best response to other firms' actions is a solution to the following profit maximization problem:

$$
\begin{aligned}
& \max _{w_{i}} \frac{B}{Q} q_{i}-w_{i} \\
& \text { s.t. } w_{i} \leq \frac{B}{Q} q_{i}, L_{i}=w_{i} \frac{L}{W}, q_{i}=f_{i}\left(L_{i}\right) .
\end{aligned}
$$

The first constraint implies that profits cannot be negative. The first-order condition of firm 1 is

$$
\begin{aligned}
& \frac{B}{Q} f_{1}^{\prime}\left(L_{1}\right)\left(\frac{L}{W}-w_{1} \frac{L}{W^{2}}\right)+B f_{1}\left(L_{1}\right)\left(-\frac{1}{Q^{2}}\right) f_{1}^{\prime}\left(L_{1}\right)\left(\frac{L}{W}-w_{1} \frac{L}{W^{2}}\right)-1=0, \\
& \Rightarrow \frac{p}{r} \frac{1}{Q W}\left(f_{2}\left(L_{2}\right)+f_{3}\left(L_{3}\right)\right) f_{1}^{\prime}\left(L_{1}\right)\left(w_{2}+w_{3}\right)=1 .
\end{aligned}
$$

Similarly, the first-order conditions of firm 2 and 3 are

$$
\begin{aligned}
& \frac{p}{r} \frac{1}{Q W}\left(f_{1}\left(L_{1}\right)+f_{3}\left(L_{3}\right)\right) f_{2}^{\prime}\left(L_{2}\right)\left(w_{3}+w_{1}\right)=1, \\
& \frac{p}{r} \frac{1}{Q W}\left(f_{1}\left(L_{1}\right)+f_{2}\left(L_{2}\right)\right) f_{3}^{\prime}\left(L_{3}\right)\left(w_{2}+w_{1}\right)=1,
\end{aligned}
$$


respectively. We denote the share of input by $s_{i}=w_{i} / W$, where $i \in\{1,2,3\}$. The aggregate output is given by $Q=A \cdot\left(s_{1} L\right)^{2}+B \cdot\left(s_{2} L\right)^{\alpha}+C \cdot s_{3} L$. Substituting $s_{i}$ and $Q$ into (18), (19), and (20), we obtain the following conditions for firms 1,2 , and 3 , respectively:

$$
\begin{aligned}
& \frac{p}{r} \frac{\left(B\left(s_{2} L\right)^{\alpha}+C s_{3} L\right) \cdot 2 A L s_{1}\left(s_{2}+s_{3}\right)}{A\left(s_{1} L\right)^{2}+B\left(s_{2} L\right)^{\alpha}+C s_{3} L}=1, \\
& \frac{p}{r} \frac{\left(A\left(s_{1} L\right)^{2}+C s_{3} L\right) \cdot B \alpha\left(s_{2} L\right)^{\alpha-1}\left(s_{1}+s_{3}\right)}{A\left(s_{1} L\right)^{2}+B\left(s_{2} L\right)^{\alpha}+C s_{3} L}=1, \\
& \frac{p}{r} \frac{\left(A\left(s_{1} L\right)^{2}+B\left(s_{2} L\right)^{\alpha}\right) \cdot C\left(s_{1}+s_{2}\right)}{A\left(s_{1} L\right)^{2}+B\left(s_{2} L\right)^{\alpha}+C s_{3} L}=1 .
\end{aligned}
$$

We can solve for the equilibrium shares from the following three equations in three variables:

$$
\begin{gathered}
\left(2 A B s_{1}\left(s_{2}+s_{3}\right) s_{2}^{\alpha}-\alpha A B s_{1}^{2}\left(s_{1}+s_{3}\right) s_{2}^{\alpha-1}\right) \cdot L^{\alpha+1}+2 A C s_{1} s_{3}\left(s_{2}+s_{3}\right) \cdot L^{2}-\alpha B C s_{3} s_{2}^{\alpha-1}\left(s_{1}+s_{3}\right) \cdot L^{\alpha}=0 \\
2 A B s_{1}\left(s_{2}+s_{3}\right) s_{2}^{\alpha} \cdot L^{\alpha+1}+\left(2 A C s_{1} s_{3}\left(s_{2}+s_{3}\right)-A C\left(s_{1}+s_{2}\right) s_{1}^{2}\right) \cdot L^{2}-B C s_{2}^{\alpha}\left(s_{1}+s_{2}\right) \cdot L^{\alpha}=0 \\
s_{1}+s_{2}+s_{3}=1 .
\end{gathered}
$$

Figure 1 demonstrates equilibrium shares for three equilibria that occur under $A=B=C=1$, and $\alpha=0.5$ as the aggregate input $L$ varies. Interestingly, in each equilibria, the share of at least one firm approaches zero as the aggregate input $L$ gets large. This, in turn, leaves three possible equilibrium industrial organization modes: i) monopoly with the decreasing-returns-to-scale firm in equilibrium 2 of Figure 1, ii) stable duopoly with increasing- and constant-returns-to-scale firms in equilibrium 1 of Figure 1, and iii) stable duopoly with decreasing- and constant-returns-to-scale firms in equilibrium 3 of Figure 1. In equilibrium 2 of Figure 1, increasing- and constant-returnsto-scale firms both make positive profits regardless of the market thickness. However, when the market is thin (i.e., $L$ is small), the decreasing-returns-to-scale firm makes positive profit; and when the market is thick (i.e., $L$ is large), the decreasing-returns-to-scale firm makes negative profit. However, in equilibrium 2 of Figure 1, when the market is thick, the decreasing-returns-toscale firm dominates the market while incurring negative profit. Thus, for all three firms to make positive profits in equilibrium 2 , the market must be sufficiently thin (i.e., $L$ is sufficiently small). In equilibrium 1 of Figure 1, all three firms make positive profits regardless of the thickness of the market. In equilibrium 3 of Figure 1, the increasing-returns-to-scale firm always makes negative profits with very small and diminishing market share, so it is likely that it will eventually exit the market, and the other two firms will share the market and earn positive profits. In this example, we can still obtain the multiplicity result if all three firms make positive profits (equilibrium 1 and 3 when market is sufficiently thin).

Figure 2 illustrates equilibrium shares for two equilibria that occur under $A=1, B=2, C=3$, and $\alpha=2 / 3$, and in both equilibria the decreasing- and constant-returns-to scale firms make positive profits. In equilibrium 1 of Figure 2, when the market is thin (i.e., $L$ is small) the increasingreturns-to-scale firm has negative profits, and when the market is thick (i.e., $L$ is large) the 

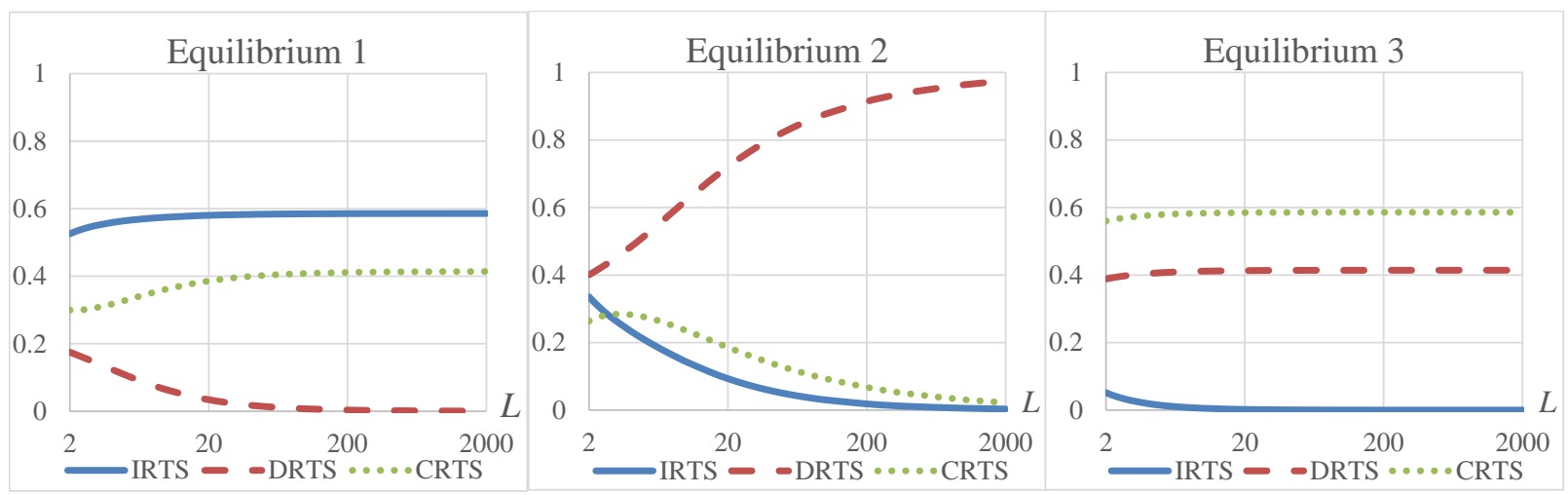

Figure 1 Input share allocations across increasing- (IRTS), decreasing- (DRTS), and constant- (CRTS) returnsto-scale firms as the aggregate input $L$ varies in logarithmic scale. Setting: $A=B=C=1, \alpha=0.5$.

increasing-returns-to-scale firm makes positive profit. The equilibrium 2 of Figure 2 is similar to the equilibrium 3 of Figure 1 in the sense that the increasing-returns-to-scale firm always makes negative profit, and has diminishing market shares and it is likely to exit the market eventually, while the other two firms share the market and earn positive profits.

The two examples above show that thin market equilibria may generate negative profits while thick market does not, and thick market equilibria may also generate negative profits while thin market does not (in which case the dominant firm will eventually exit the market). We also observe that if the increasing-returns-to-scale firm has very small market share, it makes negative profit and is likely to exit the market, while the other two firms make non-negative profits, and are likely to share the market. If the decreasing-returns-to-scale firm dominates the market, it makes negative profit; if it does not dominate the market, which is when the market is sufficiently thin, all three firms make nonnegative profits. The possibility of profits being negative in these examples reflect the fact that these examples do not calculate the full Nash equilibria for the model, but rather only the firms' responses to variations in the input to production, holding the input prices constant. In a full Nash-equilibrium calculation, firms facing negative profit would need to make an exit decision, with the final equilibria then being based on a smaller number of active firms in the market.

\section{Discussion and Conclusion}

We have shown that variants of the Shapley-Shubik market game model with production can generate an equilibration mechanism that can lead to multiple equilibria when the number of active firms is small. The equilibration process can accommodate nominal price rigidities, without any need for enforcing menu costs or other additional restraints on price adjustment. We also explicitly show the relationship between a typical firm's markup of price over marginal cost and its market 


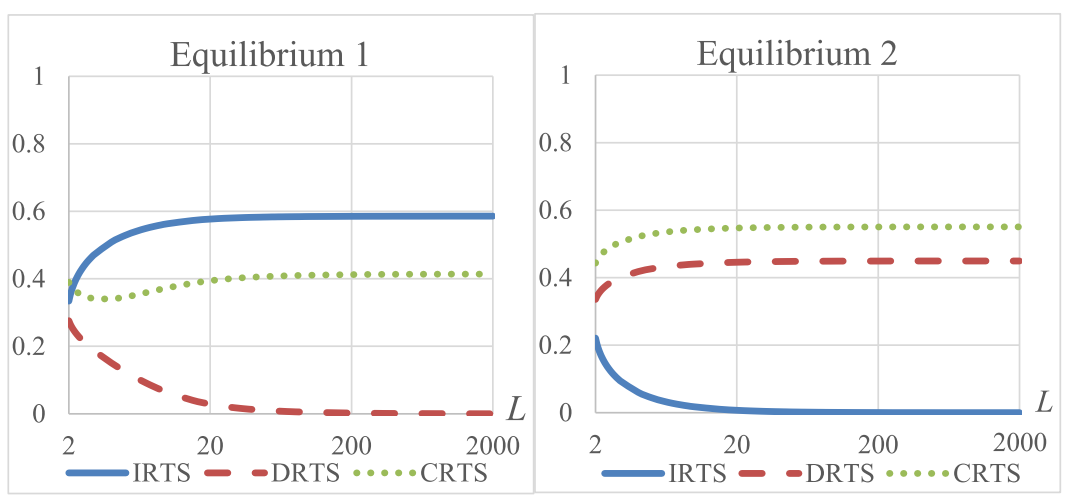

Figure 2 Input share allocations across increasing- (IRTS), decreasing- (DRTS), and constant- (CRTS) returnsto-scale firms as the aggregate input $L$ varies in logarithmic scale. Setting: $A=1, B=2, C=3, \alpha=2 / 3$.

share. The model itself is silent on what might cause price rigidities, and how different mechanisms (e.g., menu costs, search frictions, and learning) might interact with the basic model. We believe there are some interesting arguments in favor of learning and evolutionary dynamics that arise from the general equilibrium considerations in our analysis.

The problems with finding effective mechanisms for implementing equilibrium prices in competitive economies are well known. Scarf (1960)'s example shows that the presence of strong income effects can make simple price adjustment dynamics like the Walrasian tatonnement process ineffective. While the market game does provide an explicit price formation mechanism via the ratio of expenditure flows to quantity flows, Kumar and Shubik (2004) show that the market game is not immune to Scarf (1960)-like problems for simple adjustment dynamics akin to tatonnement.

On the other hand, there are a series of strong results in the literature on evolutionary game theory showing that when the Nash equilibrium to a game is strict (i.e., when the equilibrium is in pure strategies), then fitness-based (replicator) dynamics in which better responses to other agents' play are imitated lead to convergence to the Nash equilibrium. These results have not received much attention in the conventional general equilibrium analysis or related work in macroeconomics because of the time-scales on which these dynamics operate, and the often non-market-based nature of the interactions generating the convergence.

What the evolutionary game theory results do suggest (particularly in light of the fundamental problems introduced by income effects) is that equilibrium (either Nash or competitive) is something that must be learned rather than mechanically implemented. To the extent that Nash equilibria of the market game are evolutionarily stable, i.e., immune to deviations from Nash equilibrium strategies, the learning costs will be quite high since pricing experiments themselves become costly. Hence, the relatively more complex nature of evolutionary learning, as opposed to simple mechanical price adjustment processes, makes attaining an equilibrium costly, and provides an incentive for maintaining equilibrium prices once they are learned. 
From a less heterodox perspective, the literature on search and matching, based on the seminal work of Burdett and Judd (1983), is capable of generating both price stickiness and staggered price adjustment in otherwise conventional economic models. This framework, particularly at the interface between wholesale and retail intermediaries could easily be adapted to the model we have presented here.

One thing that is clear from this discussion is that further work embedding the market game with production in a dynamic quantitative setting is worth undertaking.

\section{Acknowledgments}

We thank the two anonymous referees for useful comments and James Peck for invaluable discussions during the project.

\section{References}

Aghion, P., Howitt, P., 1992. A model of growth through creative destruction. Econometrica 60 (2), 323-351.

Aghion, P., Howitt, P., 2000. On the macroeconomic effects of major technological change. In: Encaoua, D., Hall, B. H., Laisney, F., Mairesse, J. (Eds.), The Economics and Econometrics of Innovation, Chapter 2. Springer, pp. 31-53.

Benhabib, J., Farmer, R., 1994. Indeterminacy and increasing returns. Journal of Economic Theory 63, $19-41$.

Bhaskar, V., 2002. On endogenously staggered prices. Review of Economic Studies 69, 97-116.

Burdett, K., Judd, K. L., 1983. Equilibrium price dispersion. Econometrica 51 (4), 955-969.

Carvalho, C., 2006. Heterogeneity in price stickiness and the real effects of monetary shocks. Frontiers of Macroeconomics 2 (1).

Cellini, R., Lambertini, L., 2007. A differential oligopoly game with differentiated goods and sticky prices. European Journal of Operational Research 176 (2), 1131-1144.

Cooper, R., John, A., 1988. Coordinating coordination failures in Keynesian models. Quarterly Journal of Economics 103 (3), 441-463.

Dixit, A., Stiglitz, J., 1977. Monopolistic competition and optimum product diversity. American Economic Review 67 (3), 297-308.

Dubey, P., Geanakoplos, J., 2003. From Nash to Walras via Shapley-Shubik. Journal of Mathematical Economics 39, 391-400.

Dubey, P., Shubik, M., 1977. A closed economic system with production and exchange modelled as a game of strategy. Journal of Mathematical Economics 4 (3), 253-287.

Fehr, E., Tyran, J.-R., 2008. Limited rationality and strategic interaction: The impact of the strategic environment on nominal inertia. Econometrica 76 (2), 353-394. 
Fershtman, C., Kamien, M. I., 1987. Dynamic duopolistic competition with sticky prices. Econometrica 55 (5), 1151-1164.

Korpeoglu, C. G., Spear, S. E., 2016. The market game with production and arbitrary returns to scale. Online Appendix to Coordination Equilibrium, Price Stickiness, and Markup Variations in Market Games.http://repository.cmu.edu/cgi/viewcontent.cgi?article=2549\&context=tepper.

Kumar, A., Shubik, M., 2004. Variations on the theme of Scarf's counter-example. Computational Economics $24,1-19$.

Nekarda, C. J., Ramey, V. A., 2013. The cyclical behavior of the price-cost markup. Working paper, University of California, San Diego, CA.

Peck, J., Shell, K., 1990. Liquid markets and competition. Games and Economic Behavior 2, 362-377.

Peck, J., Shell, K., 1991. Market uncertainty: Correlated and sunspot equilibria in imperfectly competitive economies. Review of Economic Studies 58, 1011-1029.

Peck, J., Shell, K., Spear, S., 1992. The market game: Existence and structure of equilibrium. Journal of Mathematical Economics 21, 271-299.

President's Council of Economic Advisors Issue Brief, April 2016. Benefits of competition and indicators of market power. https://www. whitehouse.gov/sites/default/files/page/files/20160414_ cea_competition_issue_brief.pdf. Accessed on December 13, 2016.

Romer, P. M., 1990. Endogenous technological change. Journal of Political Economy 98 (5), S71-S102, part 2.

Rotemberg, J. J., Woodford, M., 1991. Markups and the business cycle. NBER Macroeconomics Annual (6), $63-140$.

Rotemberg, J. J., Woodford, M., 1992. Oligopolistic pricing and the effects of aggregate demand on economic activity. Journal of Political Economy 100 (6), 1153-1207.

Rotemberg, J. J., Woodford, M., 1999. The cyclical behavior of prices and costs. Handbook of macroeconomics 1 part b, 1051-1135.

Scarf, H. S., 1960. Some examples of global instability of the competitive equilibria. International Economic Review 1, 157-172.

Shapley, L., Shubik, M., 1977. Trade using one commodity as a means of payment. Journal of Political Economy 85, 937-968.

Slade, M. E., 1999. Sticky prices in a dynamic oligopoly: An investigation of (s,S) thresholds. International Journal of Industrial Organization 17 (4), 477-511. 


\section{Appendix}

\section{Appendix A: Proof of Theorem 1.}

We provide the proof of the generic applicability of the implicit function theorem here. It remains, then, to show that the implicit function theorem (or, more generally, a transversality result) will apply in the neighborhood of the Nash equilibrium for an economy under slack. The Jacobian matrix for the mapping defined by equilibrium conditions has $\mathcal{J} N+N$ rows (corresponding to the equilibrium first-order conditions and input price equations, respectively), and $(\mathcal{J}-1) N+$ $2 N$ columns (corresponding to the input market shares, aggregate input offers, and aggregate expenditures on inputs, respectively). For specificity, we note that we are making a change of variables in the first-order conditions by defining firm $k_{j}$ 's share of aggregate input expenditure on $\operatorname{good} n$ as

$$
s_{k_{j}}^{n}=\frac{w_{k_{j}}^{n}}{W^{n}} .
$$

Given this change of variables, variations in the aggregate level of expenditures on inputs holding input expenditure shares constant then means that each firms' expenditures scale as the aggregate does. In the input pricing equation

$$
r-\hat{E}^{-1} W=0
$$

we take $r$ as a vector of parameters indicating the input price level firms at which would like prices to remain constant. With these definitions, the Jacobian matrix is

$$
\left[\begin{array}{ccc}
\mathbf{G} & \mathbf{\Phi} & \mathbf{0} \\
\mathbf{H} & \Phi_{\mathcal{J}} & \mathbf{0} \\
\mathbf{0} & -\hat{W} \hat{E}^{-2} & \hat{E}^{-1}
\end{array}\right]
$$

The derivatives here are evaluated at the sell-all equilibrium values. The adjustments needed to show the rank result for the short-sale and low employment cases are straight-forward, so we concentrate here on the sell-all game. The derivatives of the first-order conditions with respect to aggregate input expenditures are zero because these always appear in the expenditure share terms, and not alone. The matrix $\mathbf{G}$ is given by

$$
\mathbf{G}=\left[\begin{array}{ccc}
\mathbf{G}_{1} & \cdots & \mathbf{0} \\
\vdots & \ddots & \vdots \\
\mathbf{0} & \cdots & \mathbf{G}_{\mathcal{J}-1}
\end{array}\right]
$$

where each matrix $\mathbf{G}_{k_{j}}$ for $k_{j} \in\{1,2, . ., \mathcal{J}-1\}$ on the main diagonal is an $N \times N$ matrix given by

$$
\mathbf{G}_{k_{j}}=\left[-p^{j} \frac{Q_{-k_{j}}^{j}}{Q^{j}}\left[D^{2} f_{k_{j}}-\frac{1}{Q^{j}} D f_{k_{j}} D f_{k_{j}}^{T}\right] \hat{E}+\left[\hat{W} \hat{W}_{-k_{j}}^{-1}\right]^{2} \hat{r}\right] \text {, }
$$


i.e., the matrix of derivatives of firm first-order conditions with $\hat{E}=\operatorname{diag} E$ and $\hat{r}=\operatorname{diag} r$. The $(\mathcal{J}-1) N \times N$ matrix $\boldsymbol{\Phi}$ is given by

$$
\mathbf{\Phi}=\left[\begin{array}{c}
\Phi_{1} \\
\vdots \\
\Phi_{\mathcal{J}-1}
\end{array}\right]
$$

and consists of the derivatives with respect to aggregate input offers of the firm first-order conditions, with each submatrix $\Phi_{k_{j}}$ given by

$$
\Phi_{k_{j}}=p^{j} \frac{Q_{k_{j}}^{j}}{Q^{j}}\left[D^{2} f_{k_{j}}-\frac{1}{Q^{j}} D f_{k_{j}} D f_{k_{j}}^{T}\right]\left[I-\hat{W}_{-k_{j}} \hat{W}^{-1}\right]+\hat{W} \hat{W}_{-k_{j}}^{-1} \hat{W} \hat{E}^{-2} .
$$

The matrix $\Phi_{J}$ is $N \times N$. The matrix $\mathbf{H}$ is

$$
\mathbf{H}=\left[-\mathbf{G}_{\mathcal{J}} \cdots-\mathbf{G}_{\mathcal{J}}\right]
$$

which reflects the adding up constraint on the input shares.

We note that if production functions are all concave, then each $\mathbf{G}_{j}$ is positive definite. If some production function $f$ is strictly quasi-concave, then (assuming $f$ is homogeneous of degree $\delta>1$ ), the associated derivative matrix $\mathbf{G}$ will be positive definite as long as

$$
D f^{T}\left[D^{2} f-\frac{1}{Q} D f D f^{T}\right] D f=D f^{T} D^{2} f D f-\frac{\|D f\|^{2}}{Q} D f^{T} D f=\left[(\delta-1)-\frac{\|D f\|^{2}}{Q}\right]\|D f\|^{2}<0,
$$

since the strict quasi-concavity assumption implies that the matrix is negative definite in directions orthogonal to $D f$. This condition, in turn, requires that $\delta<1+\frac{\|D f\|^{2}}{Q}$. In general, though, we can not guarantee definiteness of the $\mathbf{G}_{j}$ matrices. We can, however, guarantee that these matrices have full rank generically, and since we will need to make such genericity arguments below, we simply assume this for now.

Now, with each of the $\mathbf{G}_{j}$ matrices having full rank, we can reduce the Jacobian matrix to the following matrix

$$
\left[\begin{array}{ccc}
\mathbf{G} & \mathbf{0} & \mathbf{0} \\
\mathbf{0} & \mathbf{\Psi} & \mathbf{0} \\
\mathbf{0} & \mathbf{0} & \hat{E}^{-1}
\end{array}\right]
$$

where $N \times N$ matrix $\boldsymbol{\Psi}=\Phi_{\mathcal{J}}-\mathbf{H G}^{-1} \boldsymbol{\Phi}$.

If it turns out that the matrix $\boldsymbol{\Psi}$ is singular, then we can perturb the production functions by adding a quadratic quasi-concave perturbation of the form $\varepsilon_{k_{j}}\left(\varphi_{k_{j}}-\bar{\varphi}_{k_{j}}\right)^{T} A_{k_{j}}\left(\varphi_{k_{j}}-\bar{\varphi}_{k_{j}}\right)$ to each firm's production function, where $\varepsilon_{k_{j}}$ is strictly positive and small, $\bar{\varphi}_{k_{j}}$ is the firm's Nash equilibrium input allocation, and $A_{k_{j}}$ is an arbitrary bordered negative definite matrix, with bordering vectors colinear with $D f_{k_{j}}$. This then allows us to perturb the matrices in $\mathbf{H G}^{-1} \boldsymbol{\Phi}$ (without perturbing the gradients of firm production functions, and hence of $\boldsymbol{\Psi}$ ) and guarantee that $\boldsymbol{\Psi}$ has full rank generically. 